\title{
Moxifloxacin suppresses airway inflammation and modulates expression of caveolin-1 and flotillin-1 in airway smooth muscle cells of asthmatic rats
}

\author{
Hui-Ting $\mathrm{Li}^{1}$, Cong Ye ${ }^{1}$, Min Zhou ${ }^{2}$, Yan Yang ${ }^{1}$, Quan Jin ${ }^{3}$, Chun-Feng Pan ${ }^{3}$ \\ ${ }^{1}$ Department of Respiratory and Critical Care Medicine, Shanghai Pulmonary Hospital, Tongji University School, Shanghai 200433, China; \\ ${ }^{2}$ Department of Respiratory Medicine, Shanghai Jinshan Central Hospital, Shanghai 201500, China; ${ }^{3}$ Department of Respiratory Medicine, Jinshan \\ Hospital, Fudan University, Shanghai 201508, China \\ Contributions: (I) Conception and design: HT Li; (II) Administrative support: HT Li; (III) Provision of study materials or patients: HT Li, C Ye, M \\ Zhou, Y Yang, Q Jin; (IV) Collection and assembly of data: HT Li, C Ye, M Zhou, Y Yang, Q Jin; (V) Data analysis and interpretation: HT Li; (VI) \\ Manuscript writing: All authors; (VII) Final approval of manuscript: All authors. \\ Correspondence to: Hui-Ting Li. Department of Respiratory and Critical Care Medicine, Shanghai Pulmonary Hospital, Tongji University School, 507 \\ Zhengmin Road, Shanghai 200433, China. Email: liht0419@163.com.
}

Background: Moxifloxacin (MXF) possesses anti-inflammatory properties on asthmatic airway smooth muscle cells (ASMCs) beyond their antimicrobial effects, but the mechanisms are still unknown. This study was to investigate effects of MXF on expression of caveolin-1 (Cav-1) and flotillin-1 (FLOT1) in ASMCs in asthmatic rats.

Methods: ASMCs were collected from the airway and cultured in vitro. Cells from normal rats were treated with normal saline (Group N); cells from asthmatic rats were incubated with normal saline (Group A) or MXF (20 mg/L) (Group M); Cav-1 expression was up-regulated by transferring Cav-1 expressing lentivirus (Group L) and FLOT1 expression down-regulated by using siRNA in cells from asthmatic rats (Group S). The expressions of Cav-1, FLOT1 and p65 NF- $\mathrm{kB}$ were measured by Western blotting and quantificational real-time polymerase chain reaction (qRT-PCR), and interleukin-8 (IL-8) and eotaxin contents were measured by enzyme-linked immunosorbent assay (ELISA).

Results: Compared with normal control, Cav-1 expression significantly decreased in asthmatic groups $(\mathrm{P}<0.01)$; MXF up-regulated Cav-1 expression in asthmatic groups $(\mathrm{P}<0.01)$. However, compared with normal control, the expression of FLOT1 and $\mathrm{p} 65 \mathrm{NF}-\kappa \mathrm{B}$ dramatically increased in asthmatic groups

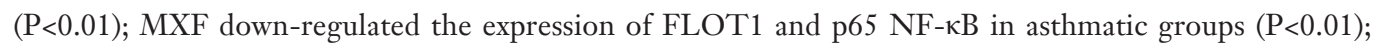
meanwhile, the expressions of FLOT1 and p65 NF- $\kappa \mathrm{B}$ decreased after up-regulation of Cav-1 expression in asthmatic groups $(\mathrm{P}=0.01)$. Compared with asthmatic groups, the IL-8 and eotaxin contents significantly decreased in MXF Groups, Cav-1 up-regulation asthmatic groups and FLOT1 down-regulation asthmatic groups $(\mathrm{P}<0.01)$.

Conclusions: MXF can modulate the airway inflammation, upregulate Cav-1 expression, downregulate the expression of FLOT1 and p65 NF- $\mathrm{B}$ in asthmatic rat ASMCs, which may be related to the antiinflammatory effects of MXF in asthmatic ASMCs.

Keywords: Moxifloxacin (MXF); caveolin-1 (Cav-1); flotillin-1 (FLOT1); airway smooth muscle cell (ASMC)

Submitted Mar 04, 2019. Accepted for publication Jul 24, 2019.

doi: $10.21037 /$ atm.2019.08.43

View this article at: http://dx.doi.org/10.21037/atm.2019.08.43 


\section{Introduction}

The characteristics of airway smooth muscle cells (ASMCs) from asthmatic patients change significantly, and they are intrinsically different from those of nonasthmatic ASMCs: hypercontractile, hyperproliferative and hypersecretory (1). Increasing evidence indicates that ASMCs can secrete significant amounts of immunomodulatory factors [e.g., interleukin-6 (IL-6), IL-8, and eotaxin], and may be indicative of an immunomodulatory role of ASMCs in regulation of airway function, as well as in airway diseases associated with acute and/or chronic inflammation, such as asthma $(2,3)$. Previous study indicates that asthmatic ASMCs could secrete more IL-8 and eotaxin than nonasthmatic ASMCs (4), which was in accordance with previous findings. Thus, ASMCs have been considered a promising "target" in the treatment of asthma (1).

Caveolae are characterized as a highly uniform structure at the plasma membrane, recently described as 'cup-shaped' structure (5), and involved in the cell signal transduction (6). Caveolin-1 (Cav-1) is the main structural component of caveolae and can be expressed in ASMCs. Recent studies indicate that Cav-1 may play an important role in regulating airway inflammation and exert protection against asthma (7), but the specific mechanism is still unclear.

Flotillin proteins are highly conserved components of lipid rafts at plasma membrane of different types of cells, and they are also involved in the cell signal transduction, cell adhesion and migration, proliferation, differentiation and endocytosis, as well as T cell activation (8-11). Recent studies reveal that flotillin-1 (FLOT1) plays an important role in the occurrence and development of malignant tumors $(12,13)$, and may serve as a prognostic factor for solid tumors $(14,15)$. Furthermore, FLOT1 can activate tumor necrosis factor-receptor signaling and sustain $\mathrm{NF}-\kappa \mathrm{B}$ activation in esophageal squamous cell carcinoma cells (16). FLOT1 is also an important mediator of TLR3 signaling in human umbilical vein endothelial cells (17), and thus may represent a novel target in the anti-inflammatory therapy. However, whether FLOT1 can regulate inflammation through $\mathrm{NF}-\kappa \mathrm{B}$ in ASMCs is still unknown.

Several studies have shown that moxifloxacin (MXF) can inhibit IL- 8 and IL- 6 secretion by activated human monocytes and human lung epithelial cells after lipopolysaccharide (LPS) treatment $(18,19)$. Previous study also revealed the inhibitory effects of MXF on the ERK1/2 activation and NF- $\mathrm{KB}$ nuclear translocation in a ASMC line (4), but the exact upstream mechanism is still unclear.

It is hypothesized that MXF may regulate the expression of Cav-1 and FLOT1, involving the anti-inflammatory effects of MXF. In this study, an asthmatic model was established in rats and ASMCs were separated from asthmatic and non-asthmatic rats and then treated with MXF. To further elucidate the role of Cav-1 and FLOT1, ASMCs from asthmatic rats received transfection with Cav-1 expressing lentiviral vector to up-regulate Cav-1 or siRNA treatment to down-regulate FLOT1, and then the protein and mRNA expressions of Cav-1, FLOT1 and p65 $\mathrm{NF}-\kappa \mathrm{B}$ and the IL-8 and eotaxin contents were measured.

\section{Methods}

\section{Culture of ASMCs and grouping}

An asthma model was established in rats $(250 \pm 5 \mathrm{mg}$, male, $\mathrm{n}=5$ ) as previously described (4), and then ASMCs were isolated from nonasthmatic (normal rats, $250 \pm 5 \mathrm{mg}$, male, $\mathrm{n}=5$ )/asthmatic rats and cultured in vitro as previously described (4). Cultures were $99 \%$ pure, and cells grew to confluence over a period of 14 to $21 \mathrm{~d}$ and were passaged when confluent. Viable cell number was assessed with a hemocytometer and trypan blue when cells were to be used for an experiment as previously described (4). Cells were subjected to immunohistochemistry for smoothmuscle a-actin and calponin. Cells of passage 5-6 were used in following experiments. Cells from nonasthmatic rats were incubated with normal saline (Group N), cells from asthmatic rats in Group A were incubated with normal saline cells from asthmatic rats in Group $M$ were treated with MXF at $20 \mathrm{mg} / \mathrm{L}$, cells from asthmatic rats in Group L were treated with Cav-1 expressing lentiviral vector to upregulate Cav-1, and cells from asthmatic rats in Group $\mathrm{S}$ were treated with FLOT1 siRNA to down-regulate FLOT1 expression.

\section{Cloning of human Cav-1 cDNA}

The sequence of human Cav-1 was cloned from mRNA isolated from Human Blood leukocytes with RNeasy mini kit (System Biosciences, Palo Alto, CA, USA). cDNA was synthesized using Reverse Transcriptase MMLV (System Biosciences). According to Human Cav-1 gene sequence from NCBI library and pcDNA-EF1-GFP vector sequence, primers were designed as follow: forward 5'-GGAATTCGGATCCGCCAGCATGTCTGGGGGC- 
3'and reverse 5'-CTCTAGATTATATTTCTTTCTGCAA GTTGATGC-3'.

\section{Construction of expression vectors and viral vector}

The purified polymerase chain reaction (PCR) amplification products and lentiviral expression vector pcDNA-EF1GFP (System Biosciences) were digested by $\mathrm{XbaI}$ and BamHI (TaKaRa, Japan), respectively. Enzyme-digested product was subjected to electrophoresis on $0.5 \%$ agarose gel to purify the product. The products after PCR enzyme digestion were connected with those after purification in the linearized vector pcDNA-EF1-GFP, which was then transduced to DH5 cells (TaKaRa). The positive clones were cultured and the plasmids extracted. The lentiviral plasmid mixture and recombinant plasmid pcDNA-EF1Cav-1 were co-transfected into $293 \mathrm{TN}$ cells (System Biosciences) according to the manufacturer's instructions. The supernatant of $293 \mathrm{TN}$ cells was collected $48 \mathrm{~h}$ later, and the titer of recombinant lentivirus was measured by gradient dilution method.

\section{Lentiviral transfection}

ASMCs of passages 4-6 were seeded to 96-well plates at $5 \times 10^{4}$ cells/well and incubated with $100,90,80,70,60$ and $50 \mu \mathrm{L}$ of $\mathrm{Lv}-\mathrm{Cav}-1$ viral supernatant independently. The fluorescence was measured $72 \mathrm{~h}$ later to determine the optimal (multiplicity of infection 2) MOI 2. ASMCs were incubated with an appropriate concentration of viral supernatant at optimal MOI, and the transfection efficiency was assessed by fluorescence imaging and immunoblotting (about 80\%).

\section{Transient transfection}

For silencing of FLOT1, ASMCs of passages 4-6 were seeded to 24-well plates at $5 \times 10^{4}$ cells/well. siRNAs (Stealth RNAi, Invitrogen, USA) in Opti-MEM (Gibco, USA) and Lipofectamine $^{\mathrm{TM}} 2000$ reagent were added ASMCs (80-90\% confluence) according to the manufacturer's instructions. Five hours post-transfection, the medium was refreshed with complete growth medium. After 60-h transfection, cells were harvested for further experiments.

\section{Western blotting of Cav-1, FLOT1 and p65 NF-кB}

After treatment with MXF $(20 \mathrm{mg} / \mathrm{L})$ for $48 \mathrm{~h}$, cells in different groups were collected and subjected to Western blotting. In brief, total protein was extracted from cells using radioimmunoprecipitation assay (RIPA) buffer, and the protein concentration was detected with bicinchoninic acid (BCA) assay. Thirty micrograms of protein for each sample were separated on sodium dodecyl sulfate polyacrylamide gel electrophoresis and then transferred onto polyvinylidene fluoride membranes (Hybond ${ }^{\mathrm{TM}}$; Escondido, CA, USA). Then, membranes were blocked with $5 \%$ nonfat milk in phosphate-buffered saline (PBS) to block non-specific binding for $1 \mathrm{~h}$, followed by incubation with monoclonal primary antibodies for Cav-1 (1:75, Abcam Biotechnology, UK), FLOT1 (1:75, Abcam Biotechnology) and anti-NF-кB p65 mouse polyclonal Ab (1:500; Santa Cruz Biotechnology, TX, USA) overnight at $4{ }^{\circ} \mathrm{C}$. GAPDH was used as an internal reference for protein normalization. The membranes were washed with PBST $(0.1 \%$ Tween in PBS) three times (10 min for each) and then incubated with peroxidase-conjugated secondary goat anti-rabbit IgG antibody (Abcam Biotechnology) $(1: 2,000)$ for $1 \mathrm{~h}$ at $37^{\circ} \mathrm{C}$. After three washes, the membranes were detected with the Amersham Imager 600 imaging system (General Electric Company, USA).

\section{Quantificational real-time PCR (qRT-PCR)}

Total RNA was extracted from cells using TRIzol reagent (Thermo Fisher Scientific, MA, USA) and transcribed into total complementary DNA (cDNA) using reversal transcription kit. The RT-PCR conditions were as follows: $37^{\circ} \mathrm{C}$ for $15 \mathrm{~min}, 85^{\circ} \mathrm{C}$ for $5 \mathrm{~s}$, and $4{ }^{\circ} \mathrm{C}$ for storage. Then, the cDNAs were used as templates for qPCR with SYBR Premix EX Taq according to the manufacturer's instructions. The qPCR conditions were as follows: $95^{\circ} \mathrm{C}$ for $30 \mathrm{~s}, 95^{\circ} \mathrm{C}$ for $5 \mathrm{~s}$, and $60{ }^{\circ} \mathrm{C}$ for $30 \mathrm{~s}$. The products from qPCR were detected with a 7900HT Fast PCR System (Applied Biosystems, CA, USA). Primer sequences were as follows:

Cav-1: forward, 5'-GCGACCCTAAACACCTCAAC-3', and reverse, 5'-ATGCCGTCAAAACTGTGTGTC-3';

FLOT1: forward, 5'-GCCCTGCATCCAACAGATCC-3', and reverse, 5'-AATGCCAGTGACTGAGATGGG-3';

p65 NF- $\kappa \mathrm{B}$ forward, 5'-ACCAACACAGACCCAGGGA GT-3' and reverse, 5'-CAGTCACCAGGCGAGTTATAG-3'.

\section{Detection of IL-8 and eotaxin contents by enzyme-linked immunosorbent assay (ELISA)}

ASMCs were suspended in DMEM supplemented with $10 \%$ 

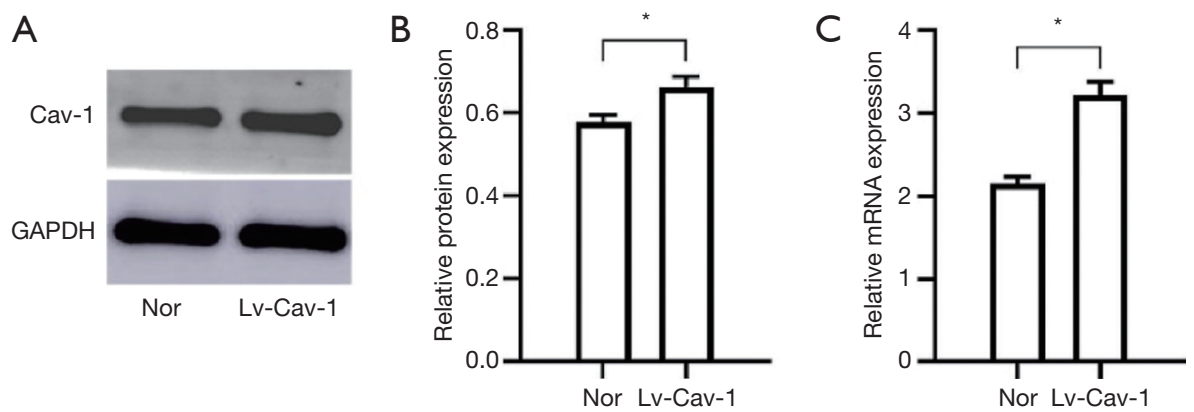

Figure 1 Consequences of Cav-1 expression up-regulation after lentiviral Lv-Cav-1 transfection. (A,B) Western blotting indicated, after transfection with Cav-1 recombinant lentiviral vectors, the protein expression of Cav-1 in Group Lv-Cav-1 significantly increased (*, $\mathrm{P}<0.05)$ vs. Group N; (C) qRT-PCR revealed the mRNA expression of Cav-1 in Group Lv-Cav-1 also significantly increased (*, P<0.05) vs. Group N. Cav-1, caveolin-1; qRT-PCR, quantificational real-time polymerase chain reaction; GAPDH, glyceraldehyde 3-phosphate dehydrogenase.

FBS and seeded at $1 \times 10^{4}$ in 24 -well plates. After incubation for $48 \mathrm{~h}$, cell-free supernatants were collected by centrifugation, and the contents of IL-8 and eotaxin were determined by ELISA (R\&D Systems, MN, USA) as previously described (4). The sensitivity of ELISA is $>10 \mathrm{pg} / \mathrm{mL}$ for IL-8, and $>5 \mathrm{pg} / \mathrm{mL}$ for eotaxin.

\section{Statistical analysis}

Data are expressed as mean \pm standard error. Statistical analyses were performed with Student's $t$-test or one-way ANOVA followed by Bonferroni's multiple comparison test for data with normal distribution according to $\mathrm{F}$ test. For data with abnormal distribution, Kruskal-Wallis-test followed by Dunns correction was used for comparisons among groups or Mann-Whitney-test for two independent groups. For paired comparisons, the Mann-Whitney-Wilcoxon-test was used. A value of $\mathrm{P}<0.05$ was considered statistically significant. Statistical analysis was performed with SPSS version 20.0.

\section{Results}

\section{Effects of Cav-1 expression after lentiviral Lv-Cav-1 transfection}

Western blotting and qRT-PCR revealed, after Lv-Cav-1 transfection, the protein and mRNA expressions of Cav-1 in ASMCs significantly increased (Figure 1), which indicated that $\mathrm{Lv}-\mathrm{Cav}-1$ was successfully transfected into ASMCs and Cav-1 expression was up-regulated in ASMCs.

\section{Silencing of FLOT1 by siRNA}

Western blotting and qRT-PCR showed the protein and
mRNA expressions of FLOT1 in cells treated with siRNA dramatically decreased (Figure 2), which indicates that FLOT1 expression was successfully down-regulated in ASMCs.

\section{Effects of MXF on Cav-1, FLOT1 and p65 NF-אB protein expression in asthmatic ASMCs}

Western blotting indicated the Cav-1 expression in Group A $(0.10 \pm 0.02)$ was significantly lower than in Group N $(0.59 \pm 0.02, \mathrm{n}=5, \mathrm{P}<0.01)$ (Figure $3 A, B)$; after MXF $(20 \mathrm{mg} / \mathrm{L})$ treatment (Group $M$ ), the Cav-1 expression dramatically increased $(0.65 \pm 0.04)$ as compared to Group $\mathrm{A}(\mathrm{P}<0.01)$ (Figure $3 A, B)$; however, there was no significant different between Group $M$ and Group L $(0.68 \pm 0.03, \mathrm{P}=0.148)$ (Figure $3 A, B)$.

qRT-PCR showed the mRNA expression of Cav-1 in Group A $(0.60 \pm 0.06)$ was significantly lower than in Group $\mathrm{N}(2.23 \pm 0.11, \mathrm{n}=5, \mathrm{P}<0.01$.) (Figure 3 C); MXF significantly up-regulated the Cav-1 mRNA expression in Group $M$ $(2.57 \pm 0.39, \mathrm{P}<0.01)$ (Figure 3C); the Cav-1 mRNA expression in Group L $(2.93 \pm 0.07)$ was also significantly higher than in Group A $(\mathrm{P}<0.01)$ (Figure $3 C)$; however, there was no significant difference between Group $M$ and Group L $(\mathrm{P}=0.062)$ (Figure 3C).

\section{Effects of MXF on FLOT1 protein and mRNA expression in asthmatic ASMCs}

The FLOT1 expression in Group A $(0.70 \pm 0.05)$ was significantly higher than in Group $\mathrm{N}(0.21 \pm 0.02, \mathrm{n}=5$, $\mathrm{P}<0.01)$ (Figure $4 A, B)$; after MXF $(20 \mathrm{mg} / \mathrm{L})$ treatment, the FLOT1 expression significantly decreased in Group $\mathrm{M}(0.55 \pm 0.03, \mathrm{P}=0.001$ vs. Group A) (Figure 4A,B); 

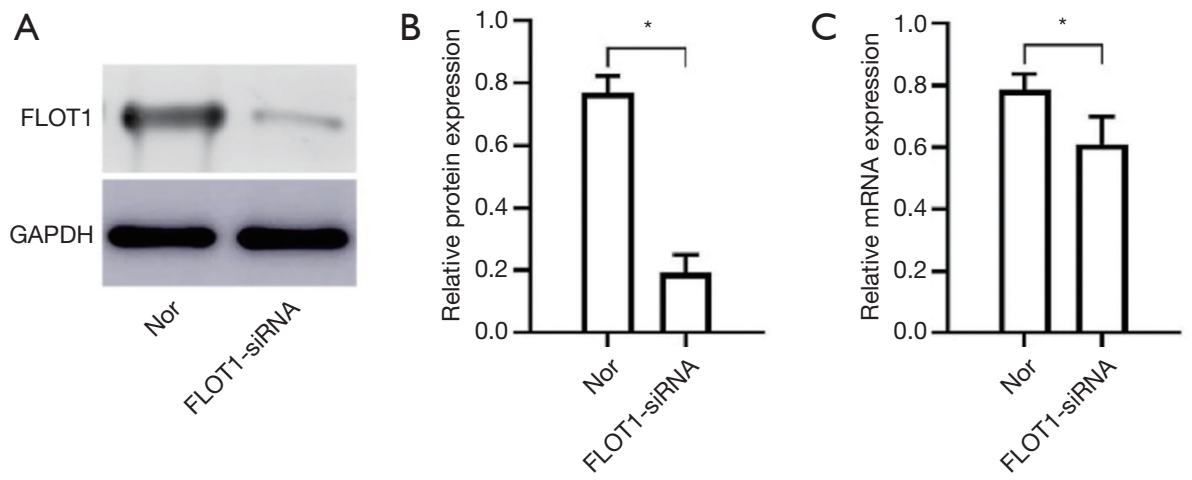

Figure 2 Consequences of FLOT1 expression silencing with siRNA. (A,B) After silencing of FLOT1 expression with siRNA, Western blotting indicated the protein expression of FLOT1 dramatically decreased in ASMCs $(*, \mathrm{P}<0.05)$; (C) qRT-PCR also revealed the mRNA expression of FLOT1 in Group FLOT1-siRNA dramatically decreased $\left({ }^{*}, \mathrm{P}<0.05\right)$ vs. Group N. FLOT1, flotillin-1; ASMCs, airway smooth muscle cells; qRT-PCR, quantificational real-time polymerase chain reaction; GAPDH, glyceraldehyde 3-phosphate dehydrogenase.
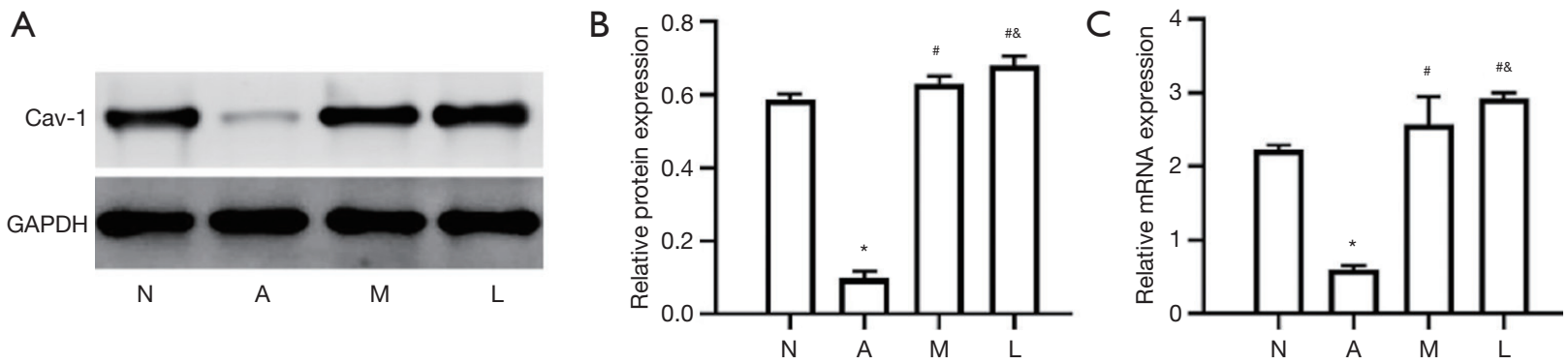

Figure 3 Effects of MXF on Cav-1 expression in nonasthmatic/asthmatic ASMCs. (A,B) Western blotting indicated the expression of Cav-1 in Group A was significantly lower than in Group N (*, P<0.01); the expression of Cav-1 in Group M and Group L dramatically increased (", P<0.01) vs. Group A; however, there was no significant difference between Group M and Group L ( $\left.{ }^{\&}, \mathrm{P}=0.148\right)$; (C) qRT-PCR showed the mRNA expression of Cav-1 in Group A was significantly lower than in Group $\mathrm{N}$ (*, $\mathrm{P}<0.01)$; MXF significantly up-regulated the mRNA expression of Cav-1 in Group $M(\#, \mathrm{P}<0.01)$; the mRNA expression of Cav-1 in Group L was also significantly higher than in Group A ( ${ }^{\#}, \mathrm{P}<0.01$ ); however, there was no significant difference between Group M and Group L ( $\left.{ }^{\&}, \mathrm{P}=0.062\right)$. MXF, moxifloxacin; Cav-1, caveolin-1; ASMCs, airway smooth muscle cells; qRT-PCR, quantificational real-time polymerase chain reaction; GAPDH, glyceraldehyde 3-phosphate dehydrogenase.

furthermore, the FLOT1 expression in Group L $(0.55 \pm 0.05)$ was also significantly lower than in Group A $(\mathrm{P}=0.001)$ (Figure $4 A, B$ ); however, the FLOT1 expression was comparable between Group L and Group M $(\mathrm{P}=0.916)$ (Figure $4 A, B)$; There was a negative correlation between Cav-1 expression and FLOT1 expression $(\mathrm{r}=-0.53, \mathrm{P}=0.04)$.

The mRNA expression of FLOT1 in Group A $(2.24 \pm 0.11)$ was significantly higher than in Group $\mathrm{N}$ $(0.69 \pm 0.03, \mathrm{n}=5, \mathrm{P}<0.01)$ (Figure $4 C) ; \mathrm{MXF}(20 \mathrm{mg} / \mathrm{L})$ significantly decreased the mRNA expression of FLOT1 in Group $\mathrm{M}(1.73 \pm 0.06, \mathrm{P}<0.01)$ vs. Group $\mathrm{N}$ (Figure $4 C$ ); the mRNA expression of FLOTI in Group L $(1.60 \pm 0.06)$ was also significantly lower than in Group A $(\mathrm{P}<0.01)$ (Figure $4 C$ ); furthermore, the mRNA expression of FLOT1 was comparable between Group $M$ and Group L ( $\mathrm{P}=0.27)$ (Figure $4 C$ ); the mRNA expression of Cav-1 was negatively related to the mRNA expression of FLOT1 $(r=-0.51$, $\mathrm{P}=0.047$ ).

\section{Effects of MXF on NF- $\mathrm{B} B$ p65 protein and $m R N A$ expression in asthmatic ASMCs}

The NF-кB p65 expression in Group A $(2.31 \pm 0.26)$ was significantly higher than in Group $\mathrm{N}(0.84 \pm 0.55, \mathrm{n}=5$, 

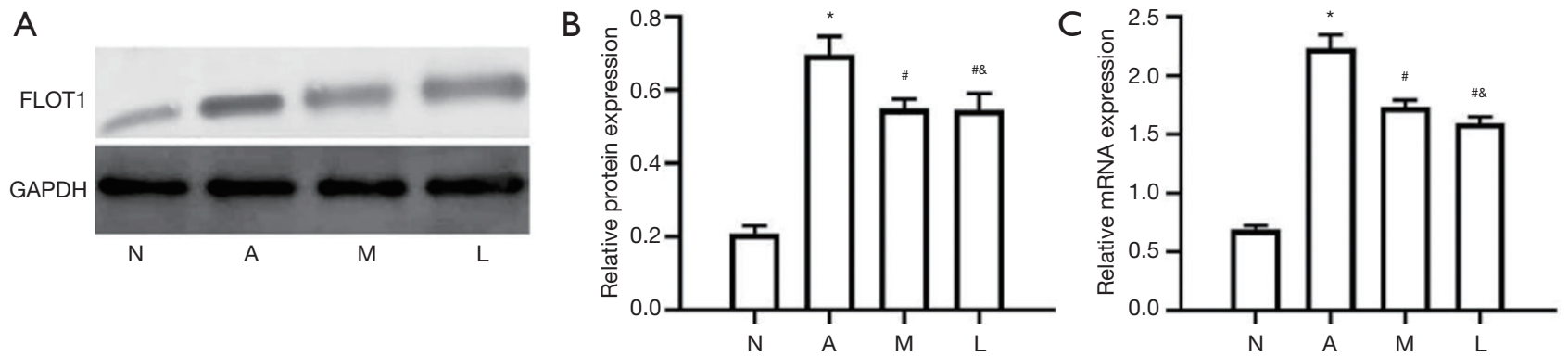

Figure 4 The FLOT1 expression in nonasthmatic/asthmatic ASMCs. (A,B) Western blotting indicated that the FLOT1 expression in Group A was significantly higher than in Group N ( $\left.{ }^{*}, \mathrm{P}<0.01\right)$; MXF significantly decreased the FLOT1 expression in Group M ( ${ }^{*}, \mathrm{P}<0.01$ ); the FLOT1 expression in Group L after lentiviral Lv-Cav-1 transfection was also significantly lower than in Group A ( $\left.{ }^{*}, \mathrm{P}<0.01\right)$; however, the FLOT1 expression in Group L was similar to that in Group M $\left(^{\&}, \mathrm{P}=0.916\right)$; (C) qRT-PCR showed the mRNA expression of FLOT1 in Group A significantly increased as compared to Group $\mathrm{N}\left({ }^{*}, \mathrm{P}<0.01\right)$; MXF significantly decreased the mRNA expression of FLOT1 in Group $\mathrm{M}\left({ }^{*}, \mathrm{P}<0.01\right)$; the mRNA expression of Cav-1 in Group L was also significantly lower than in Group A ( ${ }^{*}, \mathrm{P}<0.01$ ); furthermore, there was no significant difference in FLOT1 expression between Group M and Group L ( $\left.{ }^{\&}, \mathrm{P}=0.27\right)$. FLOT1, flotillin-1; ASMCs, airway smooth muscle cells; MXF, moxifloxacin; Cav-1, caveolin-1; qRT-PCR, quantificational real-time polymerase chain reaction; GAPDH, glyceraldehyde 3-phosphate dehydrogenase.
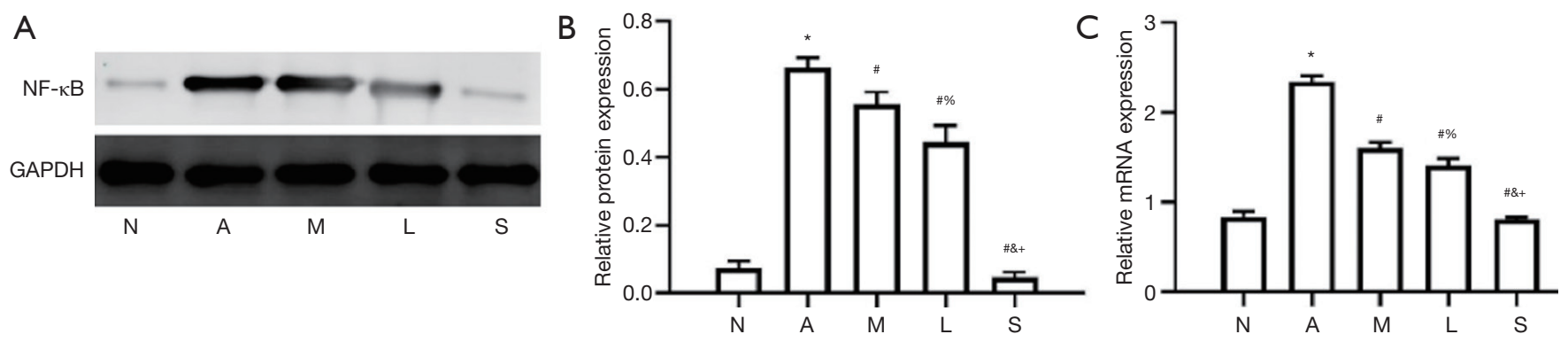

Figure 5 The p65 NF- $\kappa$ B expression in nonasthmatic/asthmatic ASMC. (A,B) Western blotting indicated the p65 NF- $\kappa$ B expression in

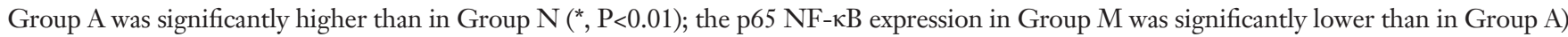

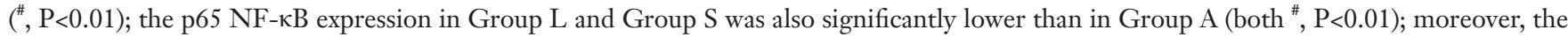
p65 NF- $\kappa$ B expression was comparable between Group $M$ and Group L $\left({ }^{\%}, \mathrm{P}=0.088\right)$. However, the p65 NF- $\kappa \mathrm{B}$ expression in Group $\mathrm{S}$ was significantly lower than in Group $\mathrm{M}$ and Group $\mathrm{L}\left({ }^{\circledR}, \mathrm{P}<0.01{ }^{+}, \mathrm{P}<0.01\right.$; respectively); (C) qRT-PCR showed the mRNA expression of p65

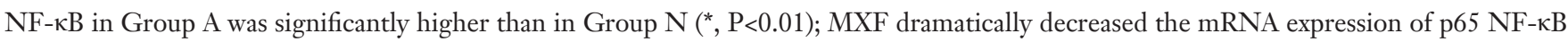

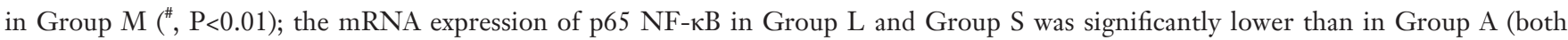
\#, $\mathrm{P}<0.01)$; furthermore, there was no significant difference between Group $\mathrm{M}$ and Group L $\left({ }^{\%}, \mathrm{P}=0.261\right)$; however, the mRNA expression of p65 NF- $\kappa$ B in Group S was significantly lower than in Group M and Group L ( ${ }^{\&}, \mathrm{P}<0.01$; ${ }^{+}, \mathrm{P}=0.008$; respectively). ASMC, airway smooth muscle cell; qRT-PCR, quantificational real-time polymerase chain reaction; GAPDH, glyceraldehyde 3-phosphate dehydrogenase.

$\mathrm{P}<0.01)$ (Figure 5A,B); MXF (20 mg/L) dramatically down-regulated the p65 NF- $\mathrm{B}$ expression in Group $M$ $(1.61 \pm 0.06, \mathrm{P}<0.01$ vs. Group $\mathrm{N}$ ) (Figure $5 A, B)$; the p65 $\mathrm{NF}-\kappa \mathrm{B}$ expression in Group L $(1.41 \pm 0.08)$ and Group S $(0.81 \pm 0.02)$ was significantly lower than in Group A (both $\mathrm{P}<0.01$ ) (Figure $5 A, B$ ); moreover, the $\mathrm{p} 65 \mathrm{NF}-\kappa \mathrm{B}$ expression was comparable between Group $M$ and Group L $(\mathrm{P}=0.08)$
(Figure $5 A, B$ ); however, the p65 $\mathrm{NF}-\kappa \mathrm{B}$ expression in Group $S$ was significantly lower than in Group $M$ and Group L $(\mathrm{P}<0.01)$ (Figure 5A,B). The Cav-1 expression was negatively related to $\mathrm{p} 65 \mathrm{NF}-\kappa \mathrm{B}$ expression $(\mathrm{r}=-0.50$, $\mathrm{P}=0.049)$; the FLOT1 expression was positively related to p65 NF- $\kappa$ B expression $(r=0.97, \mathrm{P}<0.01)$.

The mRNA expression of p65 NF- $\mathrm{B}$ in Group A 

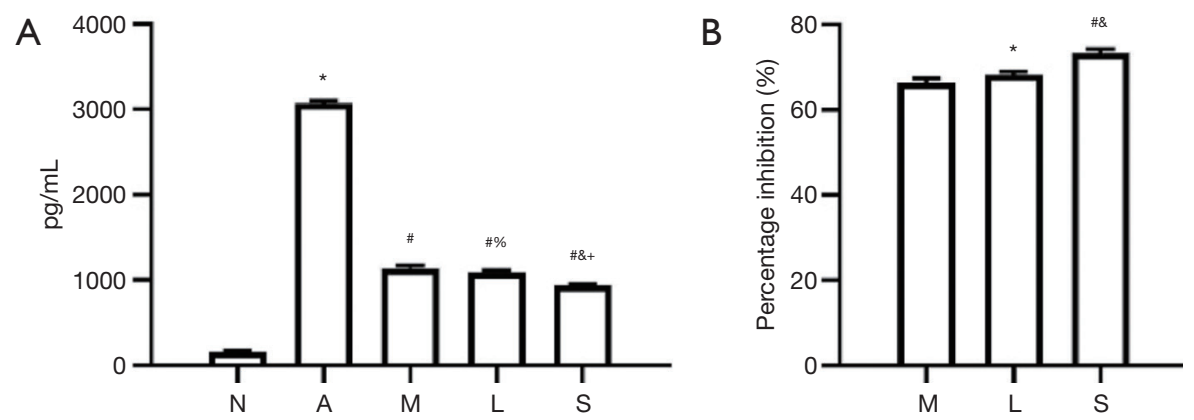

Figure 6 Effects of MXF on IL-8 secretion in asthmatic ASMCs. (A) ELISA showed that the IL-8 content in Group A was significantly higher than in Group N (*, P<0.01); the IL-8 content in Group M/L/S was significantly lower than in Group A (all \#, P<0.01); the IL-8 content in Group $M$ was similar to that in Group L ( $\left.{ }^{\%}, \mathrm{P}=0.134\right)$; however, the IL-8 content in Group S was significantly lower than in Group L ( $\left.{ }^{+}, \mathrm{P}=0.001\right)$ and Group $M\left({ }^{\&}, \mathrm{P}<0.01\right)$; (B) the IL-8 content in Group S was significantly lower than in $\mathrm{Group} M\left({ }^{\#}, \mathrm{P}<0.01\right)$ and Group L ( $\left.{ }^{\&}, \mathrm{P}=0.001\right)$, but the IL-8 content was comparable between Group M and Group L (*, P=0.059). MXF, moxifloxacin; ASMCs, airway smooth muscle cells; ELISA, enzyme-linked immunosorbent assay; IL-8, interleukin-8.

$(2.37 \pm 0.16)$ was significantly higher than in Group $\mathrm{N}$ $(1.14 \pm 0.05, \mathrm{n}=5, \mathrm{P}<0.01)$ (Figure 5C); MXF $(20 \mathrm{mg} / \mathrm{L})$ dramatically decreased the mRNA expression of p65 NF$\kappa \mathrm{B}$ in Group $\mathrm{M}(1.61 \pm 0.06, \mathrm{P}<0.01)$ (Figure $5 C)$; the mRNA expression of p65 NF- $\mathrm{kB}$ in Group L $(1.41 \pm 0.08)$ and Group S $(1.05 \pm 0.07)$ was significantly lower than in Group A (both $\mathrm{P}<0.01)$ (Figure $5 C$ ); furthermore, there was no significant difference between Group $M$ and Group L $(0.60 \pm 0.06, \mathrm{P}=0.261)$ (Figure 5C); however, the mRNA expression of p65 NF- $\kappa \mathrm{B}$ in Group $\mathrm{S}$ was significantly lower than in Group $M$ and Group $\mathrm{L}(\mathrm{P}<0.01$ and $\mathrm{P}=0.008$ respectively) (Figure 5C). The mRNA expression of Cav-1 was negatively related to the that of $\mathrm{p} 65 \mathrm{NF}-\mathrm{\kappa B}(\mathrm{r}=-0.69$, $\mathrm{P}=0.006$ ); the mRNA expression of FLOT1 was positively related to that of $\mathrm{p} 65 \mathrm{NF}-\kappa \mathrm{B}(\mathrm{r}=0.96, \mathrm{P}<0.01)$.

\section{Effects of MXF on IL-8 and eotaxin secretion in asthmatic ASMCs}

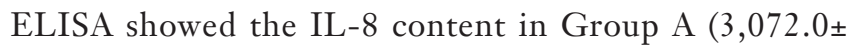
$57.2 \mathrm{pg} / \mathrm{mL}$ ) was significantly higher than in Group $\mathrm{N}$ $(166.00 \pm 8.64 \mathrm{pg} / \mathrm{mL}, \mathrm{n}=3, \mathrm{P}<0.01$ ) (Figure $6 A)$; after MXF treatment, the IL- 8 content decreased dramatically in Group $M(1,142.0 \pm 48.6 \mathrm{pg} / \mathrm{mL}, \mathrm{P}<0.01)$ (Figure $6 A)$; the IL-8 content in Group L $(1,089.0 \pm 44.4 \mathrm{pg} / \mathrm{mL})$ and Group S $(943.0 \pm 15.2 \mathrm{pg} / \mathrm{mL})$ was significantly lower than in Group A (both $\mathrm{P}<0.01$ ) (Figure $6 \mathrm{~A}$ ); the IL-8 content was comparable between Group $M$ and Group L ( $\mathrm{P}=0.134)$ (Figure 6A); however, the IL-8 content in Group $\mathrm{S}$ was significantly lower than in Group L $(\mathrm{P}=0.001)$ and Group
M $(\mathrm{P}<0.01)$ (Figure 6A). Moreover, MXF significantly inhibited IL-8 secretion to $66.40 \% \pm 0.97 \%$ in Group $M$, $68.2 \% \pm 0.84 \%$ in Group L and $73.20 \% \pm 1.06 \%$ in Group $\mathrm{S}$ (Figure $6 \mathrm{~B}$ ). The protein and mRNA expressions of Cav1 were negatively related to the IL- 8 content $(r=-0.88$, $\mathrm{P}<0.01$ and $\mathrm{r}=-0.80, \mathrm{P}=0.001$ respectively); the protein and mRNA expressions of FLOT1 were positively related to the IL- 8 content $(\mathrm{r}=0.86, \mathrm{P}<0.01$ and $\mathrm{r}=0.91, \mathrm{P}<0.01$ respectively).

ELISA showed that eotaxin content in Group A $(1,160.0 \pm 51.2 \mathrm{pg} / \mathrm{mL})$ was significantly higher than in Group $\mathrm{N}(193.00 \pm 3.94 \mathrm{pg} / \mathrm{mL}, \mathrm{n}=3, \mathrm{P}<0.01)$ (Figure $7 A)$; MXF significantly decreased the eotaxin content in Group $\mathrm{M}(669.0 \pm 10.8 \mathrm{pg} / \mathrm{mL}, \mathrm{P}<0.01)$ vs. Group N) (Figure $7 A)$; the eotaxin content in Group L $(643.0 \pm 10.3 \mathrm{pg} / \mathrm{mL})$ and Group S $(579.0 \pm 10.6 \mathrm{pg} / \mathrm{mL})$ was significantly lower than in Group $\mathrm{A}$ (both $\mathrm{P}<0.01$ ) (Figure $7 A$ ); the eotaxin content in Group $M$ was similar to that in Group $\mathrm{L}(\mathrm{P}=0.226)$ (Figure $7 A$ ); however, the eotaxin content in Group $\mathrm{L}$ and Group $M$ was significantly higher than in Group $\mathrm{S}(\mathrm{P}=0.009$ and $\mathrm{P}=0.001$, respectively) (Figure $7 A)$. Furthermore, MXF significantly inhibited eotaxin secretion to $(42.30 \% \pm 0.91 \%$ ) (Figure $7 B$ ) in Group $M$, $44.50 \% \pm 0.87 \%$ in Group L and $50.00 \% \pm 0.92 \%$ in Group $\mathrm{S}$ (Figure $7 B$ ). The protein and mRNA expressions of Cav1 were negatively related to eotaxin content $(\mathrm{r}=-0.76$, $\mathrm{P}=0.002$ and $\mathrm{r}=-0.66, \mathrm{P}=0.01$, respectively); the protein and mRNA expressions of FLOT1 were positively related to the eotaxin content $(\mathrm{r}=0.94, \mathrm{P}<0.01$ and $\mathrm{r}=0.98, \mathrm{P}<0.01$, respectively). 

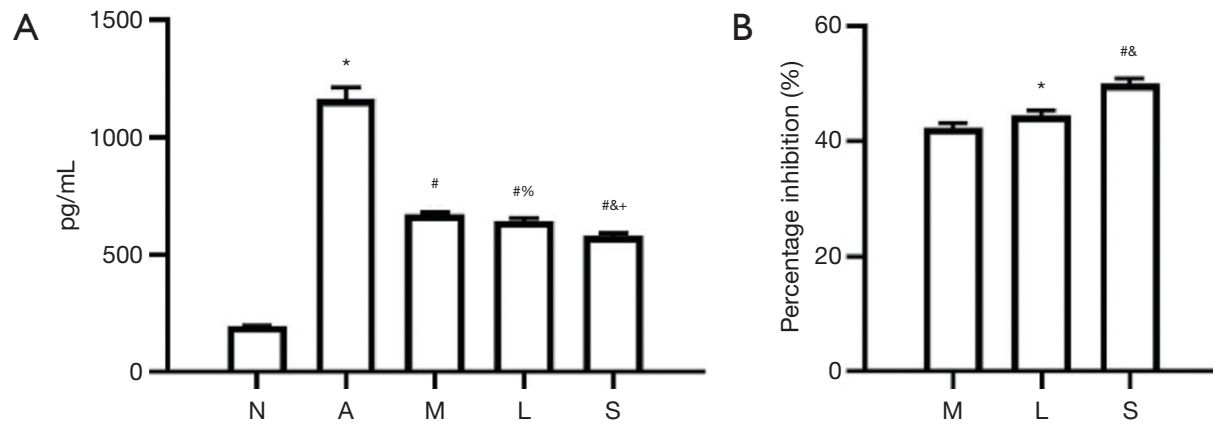

Figure 7 Effects of MXF on eotaxin secretion in asthmatic ASMCs. (A) ELISA showed that the eotaxin content in Group A was significantly higher than in Group N (*, $\mathrm{P}<0.01)$; the eotaxin content in Group M/L/S was significantly lower than in Group A (all ", $\mathrm{P}<0.01$ ); the eotaxin content in Group $M$ was similar to that in Group L ( $\left.{ }^{\%}, \mathrm{P}=0.226\right)$; however, the eotaxin content in Group L and Group M was significantly higher than in Group S ( ${ }^{+}, \mathrm{P}=0.009 ; \&, \mathrm{P}=0.001$; respectively); (B) the eotaxin content in Group $\mathrm{S}$ was significantly lower than in Group $\mathrm{M}$ ( $\left.{ }^{\#}, \mathrm{P}<0.01\right)$ and Group L ( $\left.{ }^{\star}, \mathrm{P}=0.001\right)$, but the eotaxin content was comparable between Group M and Group L (* $\left.\mathrm{P}=0.071\right) . \mathrm{MXF}$, moxifloxacin; ASMCs, airway smooth muscle cells; ELISA, enzyme-linked immunosorbent assay.

\section{Discussion}

In this study, the asthmatic model was successfully established according to previously reported (4). This study showed MXF could up-regulate Cav-1 expression in asthmatic ASMCs, but decrease the expression of FLOT1 and $655 \mathrm{NF}-\mathrm{\kappa B}$ and the secretion of pro-inflammatory factors (IL-8 and eotaxin).

Cav-1, the most extensively characterized scaffolding protein of the caveolae, has been shown to confer diverse effects, including endocytosis and membrane trafficking, signal transduction in cell growth and apoptosis, and calcium and lipid homeostasis (20). Moreover, Cav-1 innately possesses potent anti-inflammatory and immunoregulatory activities $(21,22)$. Recently, Zhu et al. (23) found that Cav-1 could play a protective role in the inflammation of diabetic neuropathy and might be a therapeutic target for diabetic neuropathy. Furthermore, Cav-1-deficient mice display significantly increased subepithelial layer thickness, which contributes to the severe airway hyperresponsiveness and inflammation (24). Hence, Cav-1 has been regarded as a potential protective factor against chronic inflammatory in asthma.

In the present study, results showed the Cav-1 expression in asthmatic ASMCs dramatically decreased, which was consistent with previous findings $(7,24)$, but after MXF treatment, the Cav-1 expression in asthmatic ASMCs significantly increased and the p65 NF- $\mathrm{\kappa B}$ expression and the secretion of pro-inflammatory factors (IL-8 and eotaxin) decreased significantly; The up-regulation of Cav-1 expression by lentiviral Lv-Cav-1 transfection in asthmatic ASMCs also decreased the p65 NF- $\mathrm{kB}$ expression and inflammatory factors (IL-8 and eotaxin). Furthermore, the Cav-1 expression was negatively related to p65 NF- $\mathrm{kB}$ expression and negatively to the contents of inflammatory factors (IL-8 and eotaxin). These findings suggest that Cav-1 may suppress airway inflammation in asthma.

Some investigators have proposed some mechanisms about the anti-inflammatory effects of Cav-1. Wang et al. (25) indicated that Cav-1 significantly attenuated proinflammatory cytokine (TNF- $\alpha$ and IL-6) production in murine macrophages via the MKK3/p38 MAPK pathway. In addition, Cav-1 can modulate inflammation through inhibiting eNOS (endothelial nitric oxide synthase) activity (26), and it can also modulate $\left[\mathrm{Ca}^{2+}\right]_{\mathrm{i}}$ signaling in human ASMCs, which may contribute to its anti-inflammatory effects on asthmatic airway (27). To further explore the exact mechanism underlying the anti-inflammation of Cav-1 in asthmatic ASMCs, the expression of FLOT1, a factor playing a key role in suppressing asthmatic airway inflammation, was detected in the present study.

There is evidence showing that FLOT1 is over-expressed in a variety of tumors and may serve as a major factor affecting the development, and metastasis of tumors (15). Recently, studies indicate that FLOT1 is also involved in the progression of other diseases, such as type 2 diabetes mellitus (T2DM) and neurodegenerative diseases (28-30). Furthermore, FLOT1 can regulate TLR3 signaling in human umbilical vein endothelial cells and may represent a novel target for the antiinflammatory therapy (17). However, whether FLOT1 can modulate inflammation in other cells and what is the specific 
mechanism are still poorly understood.

In this study, the expression of FLOT1 in asthmatic ASMC significantly increased. After MXF $(20 \mathrm{mg} / \mathrm{L})$ treatment, the expression of FLOT1 significantly decreased in the asthmatic ASMCs, which was accompanied by the marked decreases in p65 NF- $\mathrm{kB}$ expression and secretion of IL-8 and eotaxin; After silencing of FLOT1 expression with siRNA in asthmatic ASMCs, the p65 NF- $\kappa \mathrm{B}$ expression and the secretion of IL-8 and eotaxin significantly decreased. Moreover, the FLOT1 expression was positively related to $\mathrm{p} 65 \mathrm{NF}-\mathrm{\kappa B}$ expression and positively to the contents of inflammatory factors (IL-8 and eotaxin). These findings were consistent with previous results that FLOT1 can modulate the activation of NF- $\mathrm{KB}$ (16) and may represent a novel target for anti-inflammatory therapy (17). These findings suggest that FLOT1 is involved in asthmatic airway inflammation, but the specific mechanism is needed to be further explored.

It was reported that FLOT1 and Cav-1 colocalized within a cell, and knockdown of FLOT1 expression could decrease Cav-1 expression in an endoplasmic reticulum stress-dependent manner (16). However, these findings indicated that Cav-1 was negatively related to FLOT1 in asthmatic ASMCs. In asthmatic ASMCs, low Cav-1 expression was observed, but the FLOT1 expression was significantly up-regulated. After MXF $(20 \mathrm{mg} / \mathrm{L})$ treatment or transfection with lentiviral $\mathrm{Lv}$-Cav-1, the Cav-1 expression increased significantly, but the FLOT1 expression dramatically decreased. These findings suggest that MXF may up-regulate Cav-1 expression directly, but suppress FLOT1 expression indirectly; Moreover, Cav-1 may affect the FLOT1 expression in asthmatic ASMCs. In this study, after silencing of FLOT1 in asthmatic ASMCs, the contents of inflammatory factors (IL- 8 and eotaxin) were significantly lower than in MXF intervention group and lentivirus $\mathrm{Lv}-\mathrm{Cav}-1$ transfection group. The NF- $\kappa \mathrm{B}$ activation after FLOT1 silencing was also significantly inhibited than in MXF intervention group and lentivirus Lv-Cav-1 transfection group. There is evidence showing that Cav-1 can bind to FLOT1 to form heterodimers (19). Thus, it is hypothesized that, in asthmatic ASMCs, Cav-1 can bind to FLOT1 to form heterodimer, which may affect the NF- $\mathrm{KB}$ activation and reduce the secretion of IL-8 and eotaxin. More studies are needed to confirm this hypothesis.

\section{Conclusions}

In summary, MXF can increase Cav-1 expression directly and inhibit FLOT1 expression indirectly, which may be related to the anti-inflammatory effects of MXF in ASMCs from asthmatic rats.

\section{Acknowledgments}

None.

\section{Footnote}

Conflicts of Interest: The authors have no conflicts of interest to declare.

Ethical Statement: The authors are accountable for all aspects of the work in ensuring that questions related to the accuracy or integrity of any part of the work are appropriately investigated and resolved.

\section{References}

1. Zuyderduyn S, Sukkar MB, Fust A, et al. Treating asthma means treating airway smooth muscle cells. Eur Respir J 2008;32:265-74.

2. Ameredes BT. Beta-2-receptor regulation of immunomodulatory proteins in airway smooth muscle. Front Biosci (Schol Ed) 2011;3:643-54.

3. Tliba O, Amrani Y, Panettieri RA Jr. Is airway smooth muscle the "missing link" modulating airway inflammation in asthma? Chest 2008;133:236-42.

4. Li H, Zhu S, He S, et al. Anti-inflammatory effects of moxifloxacin on rat airway smooth muscle cells exposed to allergen: inhibition of extracellular-signal-regulated kinase and nuclear factor- $\kappa \mathrm{B}$ activation and of interleukin- 8 and eotaxin synthesis. Respirology 2012;17:997-1005.

5. Schlörmann $W$, Steiniger F, Richter $W$, et al. The shape of caveolae is omega-like after glutaraldehyde fixation and cup-like after cryofixation. Histochem Cell Biol 2010;133:223-8.

6. Bastiani M, Parton RG. Caveolae at a glance. J Cell Sci 2010;123:3831-6.

7. Royce SG, Le Saux CJ. Role of caveolin-1 in asthma and chronic inflammatory respiratory diseases. Expert Rev Respir Med 2014;8:339-47.

8. Affentranger S, Martinelli S, Hahn J, et al. Dynamic reorganization of flotillins in chemokine-stimulated human T-lymphocytes. BMC Cell Biol 2011;12:28.

9. Guillaume E, Comunale F, Do Khoa N, et al. Flotillin microdomains stabilize cadherins at cell-cell junctions. J 


\section{Page 10 of 10}

Cell Sci 2013;126:5293-304.

10. Langhorst MF, Reuter A, Stuermer CA. Scaffolding microdomains and beyond: the function of reggie/flotillin proteins. Cell Mol Life Sci 2005;62:2228-40.

11. Otto GP, Nichols BJ. The roles of flotillin microdomains-endocytosis and beyond. J Cell Sci 2011;124:3933-40.

12. Kang M, Ren MP, Zhao L, et al. miR-485-5p acts as a negative regulator in gastric cancer progression by targeting flotillin-1. Am J Transl Res 2015;7:2212-22.

13. Li H, Zhang Y, Chen SW, et al. Prognostic significance of flotillin1 expression in clinically N0 tongue squamous cell cancer. Int J Clin Exp Pathol 2014;7:996-1003.

14. Li Z, Yang Y, Gao Y, et al. Elevated expression of flotillin-1 is associated with lymph node metastasis and poor prognosis in early-stage cervical cancer. Am J Cancer Res 2015;6:38-50.

15. Liu XX, Liu WD, Wang L, et al. Roles of flotillins in tumors. J Zhejiang Univ Sci B 2018;19:171-82.

16. Song L, Gong H, Lin C, et al. Flotillin-1 promotes tumor necrosis factor- $\alpha$ receptor signaling and activation of NF- $\mathrm{\kappa B}$ in esophageal squamous cell carcinoma cells. Gastroenterology 2012;143:995-1005.e12.

17. Fork C, Hitzel J, Nichols BJ, et al. Flotillin-1 facilitates toll-like receptor 3 signaling in human endothelial cells. Basic Res Cardiol 2014;109:439.

18. Donnarumma G, Paoletti I, Buommino E, et al. Antiinflammatory effects of moxifloxacin and human betadefensin 2 association in human lung epithelial cell line (A549) stimulated with lipopolysaccharide. Peptides 2007;28:2286-92.

19. Shalit I, Halperin D, Haite D, et al. Anti-inflammatory effects of moxifloxacin on IL-8, IL-1beta and TNF-alpha secretion and NFkappaB and MAP-kinase activation in human monocytes stimulated with Aspergillus fumigatus. J Antimicrob Chemother 2006;57:230-5.

20. Anderson RG. Caveolae: where incoming and outgoing messengers meet. Proc Natl Acad Sci U S A

Cite this article as: Li HT, Ye C, Zhou M, Yang Y, Jin Q, Pan CF. Moxifloxacin suppresses airway inflammation and modulates expression of caveolin-1 and flotillin-1 in airway smooth muscle cells of asthmatic rats. Ann Transl Med 2019;7(18):469. doi: 10.21037/atm.2019.08.43
1993;90:10909-13.

21. Codrici E, Albulescu L, Popescu ID, et al. Caveolin-1knockout mouse as a model of inflammatory diseases. J Immunol Res 2018;2018:2498576.

22. Parat MO. The biology of caveolae: achievements and perspectives. Int Rev Cell Mol Biol 2009;273:117-62.

23. Zhu T, Meng Q, Ji J, et al. TLR4 and Caveolin-1 in monocytes are associated with inflammatory conditions in diabetic neuropathy. Clin Transl Sci 2017;10:178-84.

24. Gabehart KE, Royce SG, Maselli DJ, et al. Airway hyperresponsiveness is associated with airway remodeling but not inflammation in aging Cav1-/- mice. Respir Res 2013;14:110.

25. Wang XM, Kim HP, Song R, et al. Caveolin-1 confers antiinflammatory effects in murine macrophages via the MKK3/p38 MAPK pathway. Am J Respir Cell Mol Biol 2006;34:434-42.

26. Santizo RA, Xu HL, Galea E, et al. Combined endothelial nitric oxide synthase upregulation and caveolin-1 downregulation decrease leukocyte adhesion in pial venules of ovariectomized female rats. Stroke 2002;33:613-6.

27. Sathish V, Abcejo AJ, Thompson MA, et al. Caveolin-1 regulation of store-operated $\mathrm{Ca}(2+)$ influx in human airway smooth muscle. Eur Respir J 2012;40:470-8.

28. Chen K, Wu Q, Hu K, et al. Suppression of hepatic FLOT1 (flotillin-1) by type 2 diabetes mellitus impairs the disposal of remnant lipoproteins via syndecan-1. Arterioscler Thromb Vasc Biol 2018;38:102-13.

29. Lu Z, Liu Y, Shi Y, et al. Curcumin protects cortical neurons against oxygen and glucose deprivation/ reoxygenation injury through flotillin-1 and extracellular signal-regulated kinase1/2 pathway. Biochem Biophys Res Commun 2018;496:515-22.

30. Reisinger SN, Kong E, Molz B, et al. Flotillin-1 interacts with the serotonin transporter and modulates chronic corticosterone response. Genes Brain Behav 2019;18:e12482. 